\title{
Office Automation Sub-Summary of the Work and the Project Management System
}

\author{
Biqing $\mathrm{Li}^{1 \text {, a }}$, Zhao $\mathrm{Li}^{2, \mathrm{~b} \text {,* }}$ \\ ${ }^{1}$ College of Mechanical and Electronic Engineering, Hezhou University, Hezhou Guangxi 542899, \\ China \\ ${ }^{2}$ Management Engineering Department, Guangxi vocational and technical college of \\ communications, Liuzhou Guangxi 545000, China \\ ajanliful@163.com, b229292710@qq.com
}

Keywords: Microsoft Visual 2010; Microsoft SQL Server2005; Office automation; OA; B/S model; ASP.NET.

\begin{abstract}
This paper uses the interview object thought to analyze some of the core technology, telling the office automation development process, operation process and system. This paper mainly research on the office automation system (OA) function as the foundation, uses current more popular B/S (Browser / server) structure and ASP.NET technology development, the use of Windows 7, Microsoft Visual 2010 and Microsoft database, SQL Server2005 as the development platform, design and develop a more perfect OA system. By analyzing the system of a series of needs analysis, outline design, detailed design, coding, testing, software delivery, acceptance of the operation, the system has realized the summary of the work and project management 2 functional modules. Friendly interface, easy to operate, as long as the master of the Windows operating system and Web simple operation, can basically use the system.
\end{abstract}

\section{The development background}

The swift and violent development of internet or intranet provides exchanging and sharing of information and team collaboration with technical guarantee, and at the same time indicates the era of networked working comes. Utilize network communication foundation and advanced network application platform to establish a safe, reliable, open, efficient information network and office automation, information management electronization system, to provide administration section with modern daily working condition and abundant integrated information service, improving office efficiency and the level of management, and achieving the standardization, electronization, standardization of daily business work in various departments of enterprises and institutions, at the same time enhancing the archival manageability, the realization of online query of information, the ultimate realization of no paper office.

\subsection{Analysis on system requirement}

There are two users, among them one is ordinary user (not the office user), and the authority is to upload document, download and view their own document; the other is the office user, with maximum authority, and they can upload document, download, view and delete all users' documents;

\subsection{Project management}

There are five pages, including project import, project editor, project reminder, project query, and project export. Two kinds of users, one is the ordinary user (not the development branch user), and the authority is to visit a page in project query; the other is the development branch user, with maximum authority, and they can visit all pages in the module of project management.

\subsection{Project import}

The basic information of science and technology bureau's project is imported into the database through the development branch user using the form of excel sheet.

\subsection{Project editor}

The project editor edits, modifies, and deletes the existing project information. 


\subsection{Project reminder}

The projects that already have acceptance date are displayed in a table according to the order of ascending time, and cancel reminder: the record is not the reminder page of the current project, delay: the deadline is changed to the first day of next month.

\subsection{Project query}

The project query provides six query conditions: by year, by the level of application project, by special type, by project name, by the unit of project application, by contract number, six conditions can be together to carry on fuzzy query.

\subsection{Project export}

The project export can select the information that will be exported into the excel sheet according to the condition that needs to be exported.

\section{System design}

\subsection{The design of system summary}

Through further understanding on the previous analysis of demand, combine with the design method of oriented data stream, and the work summary platform includes: upload document, download document, view the document online and delete document(office user's authority ).Function structure chart as shown in figure 2-1.The project management platform includes 5 pages: project import ,project editor, project reminder, project query, and project export, in which ordinary user only has the authority of visiting the page of project query.

\subsection{The design of database table}

The system uses the SQL Server 2005 database, the collection of the above E-R chart, and the work summary table is used to store the document information uploaded by the user, as shown in table 1.

Table 1 . Work summary table

\begin{tabular}{|c|c|c|c|c|c|}
\hline $\begin{array}{c}\text { Column } \\
\text { name }\end{array}$ & Data type & Length & $\begin{array}{c}\text { Allow } \\
\text { empty }\end{array}$ & Default value & Illustration \\
\hline ID & int & 4 & no & & Primary key \\
\hline yhbh & nvarchar & 5 & no & User number \\
\hline scsj & datetime & 8 & no & getdate & Upload time \\
\hline wjlj & nvarchar & 100 & no & & File path \\
\hline wjmc & nvarchar & 50 & no & & $\begin{array}{c}\text { File name } \\
\text { (xxx_yyyMMddhhmmssfff.doc) }\end{array}$ \\
\hline scbz & bit & 1 & 0 & & Deletion mark(0 no; 1 yes) \\
\hline
\end{tabular}

\subsection{The design of view}

In the process of implemention, use the view to complete some multi-table queries and other operations in order to ensure the security of data and convenient data handling.

Gzzj_Grxx view takes the user number (yhbh) of work summary table (Gzzj) and the personnel number (rybh) of personal information table (Grxx) as junction conditions, and obtain the current logged-on user name (xm).

\section{System implement}

This system uses Microsoft SQL Server 2005 as database, Microsoft Visual 2010 as development platform, using $\mathrm{C} \#$ language to write program, and using the $\mathrm{B} / \mathrm{S}$ structure, generally using hierarchical structure to implement system function, namely simple factory-type three-layer architectures. The three-layer architectures are as follows: presentation layer (UI), business logic layer (BLL) and data access layer (DAL), layer by layer downward, "Each performs its own functions."

The presentation layer(UI); mainly presents Web mode, and is to receive user's request and the return of data(result), and is the interface that users interact with the system.

The business logic layer (BLL): is in between the data access layer and the presentation layer, mainly responsible for the operation on the data access layer, and serves as a connecting link between the preceding and the following. It is the most valuable core part of system architecture, and the 
relationship between layer and layer is the relationship of coming down. The bottom layer is the condition of low coupling "ignorance" for the upper layer, which indicates that the design of layer has no effect on the business logic layer. The layer stores some arithmetics that program needs and business related policy, ect. For the presentation layer, the business logic layer is the callee. Through visiting data, return data (list) and other informations.

The data access layer: mainly responsible for the operation on the data, each function only completes a task. For the business logic layer, the data access layer is the callee, and provides the business logic layer with service.

Summary function implement

The module of work summary is the staff's work report over a period of time, and office workers have the maximum authority, and they can view, download, and delete work reports that are uploaded to the database by all staff; And like the authority that the ordinary users originally have, they have the authority of uploading, downloading and viewing their own documents.

\section{Summary}

The system is the established OA network-based office system, and the part of program code is mainly written by 2 teachers and 3 students. I am responsible for the two modules, and they are work summary and project management. The frame is established by the teacher. I began to be the first contact with the actual project development, and the work summary module is guided by the teacher to complete. I am involved in the project management module from the beginning to the end, from collecting materials in science and technology bureau, establishing project management data sheet, and completing function code. The teacher gave me a great help in completing the task, and the knowledge that I have learned in the project will affect the road of my future web development.

\section{Acknowledgements}

This work is supported the following fund:

2015 college students' innovative training program: "Research on the application of value added travel experience in the mobile terminal of the 'ethnic custom travel' in Guangxi" (No 201511838070); \&\& "The design and development HeYuanTong Campus Mobile Phone APP based on Android" (No 201511838034).

2015 Teaching case project construction project of Hezhou University: "Tourist positioning and guiding system project of Huangyao scenic"; \& "Development and application of the information management system of "Huang Yao Tong"'.

Project of scientific research and technology development project of Hezhou: "Design and implementation of agricultural products e-commerce platform based on Semantic Technology" (No, Hekeneng 1506006).

Scientific research project of Hezhou university: "Research and development of E-government platform based on mobile terminal" (No 2015ZZZK03).

\section{References}

[1].Zheng SQ, DZ; Qiang, Z; Li, BQ. Design and Implementation of Supermarket Personnel Management System Based On Java. In: Chen PZ, S, editor. 2nd International Conference on Education, Management and Computing Technology (ICEMCT); Tianjin, PEOPLES R CHINA: ATLANTIS PRESS; 2015. p. 1724-7.

[2].Li BG, WL; Zheng, SY; Yue, XG. OPTIMISATION DESIGN OF CORN PRECISION SEEDER BASED ON MULTI-ROUTE AND MULTI-CHANNEL CONTROL [J]. JOURNAL OF THE BALKAN TRIBOLOGICAL ASSOCIATION. 2015, 21(4A): 1215-23.

[3].Zheng SG, Weili; Li, Biqing. Social Work in Teen Addiction Correction Services Research under the New Situation. In: Wang JX, P, editor. 4th National Conference on Electrical, Electronics and Computer Engineering (NCEECE); Xian, PEOPLES R CHINA: Atlantis Press; 2016. p. 252-5. 